\title{
Fuzzy AHP - DEMATEL Methods to Investigate Passengers' Decision Factors on Using Public City Bus in an Indonesian Region
}

\author{
V. Reza Bayu Kurniawan ${ }^{1}$, Trisna Yulianti ${ }^{2}$, Fransiska Hernina Puspitasari ${ }^{3}$ \\ 1,2Department of Industrial Engineering, Universitas Sarjanawiyata Tamansiswa, Yogyakarta, Indonesia \\ ${ }^{3}$ Department of Industrial Engineering, Universitas Atma Jaya Yogyakarta, Yogyakarta, Indonesia \\ email: reza.kurniawan@ustjogja.ac.id \\ doi: https://doi.org/10.31315/opsi.v14i1.4478
}

Received: $10^{\text {th }}$ February 2021; Revised: 23 $3^{\text {rd }}$ April 2021; Accepted: 28 ${ }^{\text {th }}$ April 2021; Available online: $24^{\text {th }}$ June 2021; Published regularly: June 2021

\begin{abstract}
An advanced public transportation system becomes an indicator for a country. Accordingly, it is essential that the decision-makers (DMs) conduct an initial study based on passengers'view in order to improve the public transportation services. Since involving multi factors, the problem is often solved using the multi-criteria decisionmaking (MCDM) approaches. This study aims to examine significant factors on passenger decision making to use public transportation using Fuzzy AHP and DEMATEL. The Fuzzy AHP method is proposed to determine criteria weights so that significant criteria are obtained, then the causal relations including the criteria are visualized using DEMATEL. This study demonstrates the integration of the two MCDM methods in a BRT system in the region of Yogyakarta, Indonesia, and invites passengers and the DMs. The result indicated that 21 criteria are identified, while the 11 significant criteria are selected based on the Fuzzy AHP weight- $\alpha$-cut screening. Besides, the DEMATEL has succeeded in describing the influence relationship for the criteria, where firstly, the significant criteria are classified into cause and effects group and secondly, the two criteria, namely coverage to strategic points and on time arrival, should be put on the top priority list. This study enables the DMs to solve public transportation problems more effectively. However, the follow-up study should be carried out by including other factors such as economic and sustainability to strengthen the decision-making process.
\end{abstract}

Keywords: public transportation; MCDM, Fuzzy AHP; DEMATEL

\section{INTRODUCTION}

In today's connected world, many countries have increased their commitment to massively provide adequate public transportation served to their people. This becomes a priority particularly in developing countries in which public awareness on using public transportation has not been an interest as well as poor infrastructure. In Indonesia, for instance, people in 2019 who use public transportation in the capital city which has the most connected transportation modes nationwide have only reached $30 \%$ of the $60 \%$ target despite an increase in passengers from 47.5 million per day in 2015 to 88 million per day in 2019 (Lova, 2019). On the other hand, there was a considerable growth in the number of private vehicles with an average increase of $10.58 \%$ for private cars and $5.07 \%$ for motorbikes between 2014 and 2018 (Informasi
Transportasi 2018, 2019). This indicates that Indonesian people prefer to use private vehicles rather than to take public transportation.

Many factors have caused poor public interest, particularly in Indonesia, in using public transportation. Aminah (2018) stated that modest accessibility, service, and the high costs caused people to be reluctant to choose public modes. Further, Azali et al (2018) in the initial survey explained that uncertainty of time and lack of information were service factors which cannot be provided in a public transportation system in a city. In fact, there are many benefits when people use public transportation in terms of financial efficiency, environment risks reduction, and good impacts on people's health ("8 Keuntungan", 2019). Therefore, to support the decision-makers (DMs) to improve public access, this study aims to evaluate what key factors affect a passengers' decision when 
choosing public transportation and the relationship among these factors.

This study proposes multi-criteria decisionmaking (MCDM) approaches including fuzzy analytic hierarchy process (Fuzzy AHP) to determine the most significant passenger decision factors and the DEMATEL method to examine the causal relations among the significant factors illustrated by the digraph. Previously, MCDM methods have been taken by many scholars to evaluate the decision-making process in transportation sector. Zapolskytè et al (2020) evaluated the urban mobility system's smartness level using AHP. Moslem et al (2020) conducted a comparative study using the two MCDM methods, namely analytic hierarchy process (AHP) and best-worst method (BWM), to obtain the significant service quality criteria of public transportation. The study involved four criteria at level 1 including service quality, transport quality, tractability, and fare, 14 criteria at level 2, and 10 criteria at level 3 . The extended AHP for public transportation decision-making has also been carried out by Duleba and Moslem (2018) and Nassereddine and Eskandari (2017). Duleba and Moslem (2018) developed an AHP combined with Kendall rank to introduce a new model of public transportation development in a Turkish city involving three distinct stakeholders, which are: passengers, potential passengers, and local government. Meanwhile, Nassereddine and Eskandari (2017) assessed passengers' satisfaction level when using several transport modes in Tehran, such as metro, taxi, BRT, bus, and van. Then, the study proposed group analytic hierarchy process (GAHP) and preference ranking organization method for enrichment of evaluation (PROMETHEE). By identifying six criteria, namely travel cost, travel time, waiting time, suitability, accesibility, and safety, the result indicated that metro was the most preferred mode.

More specific studies on public transportation performance evaluation using MCDM techniques have also been carried out by several researchers. Chen (2016) and Bakır et al (2019) evaluated the service quality performance for the airlines industries. Chen (2016) developed a case study in the Taiwanese airline industry using DEMATEL and ANP, while Bakır et al (2019) demonstrated for European LCCs (low cost carriers) using
Entropy and WASPAS. Although there was a difference in defining criteria, several criteria were relevant for both studies such as service, management, and convenience. Another study undertaken by Kiani Mavi et al (2018) developed an integrated simulation and MCDM approach to improve BRT performance in Tehran with four improvement scenarios. The research considered grey step-wise weight assessment ration analysis (SWARA-G) to determine the criteria weight and grey complex proportional assessment of alternatives (COPRAS-G) to rank scenarios. Further study demonstrated in a rail mode conducted by $\mathrm{Li}$ et al (2020) evaluated passenger satisfaction level when taking the rail transit network in Shanghai using phytagorean fuzzy sets and multiobjective optimization by a ratio analysis plus full multiplicative form method (MULTIMOORA). Hence, many studies have considered that MCDM is both relevant and effective method for evaluating public transportation performance as well as assessing passenger satisfaction because involving multiple criteria and alternatives for decisionmaking improvements.

To determine the criteria weight of passengers' decision factors, the AHP method extended to fuzzy sets is proposed in this study. Mardani et al (2016) in the systematic review involving 89 papers desribed that various MCDM methods such as AHP, ANP, Entropy, TOPSIS, VIKOR, MULTIMOORA, and many others have been widely used in transportation system decision-making problems. Further, Mardani et al (2016) indicated that AHP and Fuzzy AHP were the most preferred method pertaining to transportation system problems due to the simplicity of computation and theoritical understanding compared to the others, while the fuzzy environment defines the ambiguity that cannot be explained in the traditional AHP. Subsequently, the DEMATEL method is also selected to describe the influential relationship among the significant criteria that are previously obtained using Fuzzy AHP. A case study on the bus rapid transit (BRT) system served for the region of Yogyakarta Indonesia, Transjogja, is demonstrated. The region has become one of the national tourist development priorities which serves a huge number of domestic and foreign tourists daily. Therefore, the region's public 
access has an essential part to provide a good urban mobility.

Previously, the evaluation of Transjogja performance have been conducted by several studies. Sutari and Herlina (2020) and Wibowo (2014) examined the service level of Transjogja using statistical approaches. Further, the servqual analysis has also been added by Sutari and Herlina (2020) which indicated a gap between passengers' expectations and reality. Besides, Transistari (2017) and Octaviantari (2016) evaluated the performance of BRT Transjogja using an importance-performance analysis (IPA) approach and classified the variables into four quadrants. Sutari and Herlina (2020) and Transistari (2017) identified five variables, which are: tangibles, reliability, responsiveness, assurance, and emphaty, while Octaviantari (2016) categorized 14 indicators into four variables, namely safety, comfort, affordability, and equality. To sum up, it can be concluded that the evaluation of the Yogyakarta's BRT system requires multi factors which are considered as an MCDM problem, while no previous studies has measured the performance of the transport system using the method. Therefore, this study will fill the gap by applying MCDM approaches to investigate the significant factors influencing passengers' decision on using the city transportation system exhaustively.

\section{METHOD}

This research consists of two main scopes: first, to determine the criteria weights which represent the significant criteria of passenger decision-making when using the BRT system, and second, to examine the causal relations among the significant criteria. Then, there are four steps to achieve these two scopes: (1) identifying a hierarchical structure of the decision-making, (2) calculating the weight of criteria, (3) screening the criteria, and (4) developing causal relations through a digraph.

\subsection{Calculating the weight of criteria using Fuzzy AHP}

The Fuzzy AHP method is a technique developed from traditional AHP to solve complex decision-making problems since the method is able to cover AHP' crisp scales limitation through natural linguistic terms (Chou et al, 2019). The Fuzzy AHP calculation begins with converting crisp sets to fuzzy sets, and then calculating the weights using the geometrical mean as described in the following steps.

\subsubsection{Defining the fuzzy traingular scales}

The fuzzy numbers consist of three parameters, namely the lower $(l)$, the mean $(m)$, and the upper bonds $(u)$. Accordingly, the corresponding AHP's fuzzy numbers is provided in Table 1 describing Saaty - fuzzy scales conversion according to the linguistic definition.

Table 1. Linguistic terms and the corresponding TFNs (Chou et al., 2019)

\begin{tabular}{clc}
\hline $\begin{array}{c}\text { Saaty } \\
\text { Scale }\end{array}$ & Definition & $\begin{array}{c}\text { Fuzzy } \\
\text { Triangular Scale }\end{array}$ \\
\hline 1 & Equally important & $(1,1,1)$ \\
3 & Weakly important & $(2,3,4)$ \\
5 & Fairly important & $(4,5,6)$ \\
7 & Strongly important & $(6,7,8)$ \\
9 & Absolutely important & $(9,9,9)$ \\
\hline 2 & Intermittent values & $(1,2,3)$ \\
4 & between two adjacent & $(3,4,5)$ \\
6 & scales & $(5,6,7)$ \\
8 & & $(7,8,9)$ \\
\hline
\end{tabular}

\subsubsection{Developing the fuzzy pairwise comparison matrices}

The pairwise comparison matrice (1) indicates the elements of $\widetilde{d_{l j}^{k}}$ in AHP fuzzy scales which represents $k^{\text {th }}$ decision makers' preference of the $i^{\text {th }}$ criterion over the $j^{\text {th }}$ criterion.

$$
\tilde{A}^{k}=\left[\begin{array}{cccc}
\widetilde{d_{11}^{k}} & \widetilde{d_{12}^{k}} & \cdots & \widetilde{d_{1 n}^{k}} \\
\widetilde{d_{21}^{k}} & \cdots & \cdots & \widetilde{d_{2 n}^{k}} \\
\cdots & \cdots & \cdots & \cdots \\
\widetilde{d_{n 1}^{k}} & \widetilde{d_{n 2}^{k}} & \cdots & \widetilde{d_{n n}^{k}}
\end{array}\right]
$$

\subsubsection{Calculating the fuzzy weight of criteria}

The fuzzy weights is obtained using the geometrical technique (2) so that the fuzzy weights can be calculated using equation (3). The equation (2) and (3) below are summarized from Chou et al. (2019)

$$
\begin{aligned}
& \bar{r}_{l}=\left(\prod_{j=1}^{n} \bar{d}_{i j}\right)^{1 / n}, i=1,2, \ldots, n \\
& \bar{w}_{i}=\bar{r}_{i} \otimes\left(\bar{r}_{1} \oplus \bar{r}_{2} \oplus \ldots \oplus \bar{r}_{n}\right)^{-1}
\end{aligned}
$$

2.1.4 Calculating the average and the normalized weight criteria 
The normalized weight represents the criteria weight is calculated using equation (4) as cited from Chou et al. (2019) .

$$
\begin{aligned}
& M_{i}=\frac{\bar{w}_{1} \oplus \bar{w}_{2} \oplus \ldots \oplus \bar{w}_{n}}{n} \\
& N_{i}=\frac{M_{i}}{M_{1} \oplus M_{2} \oplus \ldots \oplus M_{n}}
\end{aligned}
$$

\subsection{Screening the criteria}

The next step is screening the criteria via the critera weight value obtained by the Fuzzy AHP and the threshold value, $\alpha$-cut, calculated using equation (6) for $n$ criteria. The criteria with weight value greater than the $\alpha$-cut are then selected and represent the relatively important, while the unselected criteria are relatively unimportant (Yang et al 2020).

$$
\alpha-\mathrm{cut}=\frac{1}{n}
$$

\subsection{Developing causal relations through a digraph}

The DEMATEL method is proposed since the method is able to visualize a causal diagram describing the influential relations of the criteria. In this study, the DEMATEL is operated based on Shieh et al (2010) and Yazdani et al (2020) procedure.

\subsubsection{Developing the initial direct relation matrix (A)}

The initial stage of the DEMATEL method is generating an $n \times n$ direct-relation matrix $(A)$. Both the DEMATEL and the AHP have the same first step which initially develop the decision-making matrices representing the preference level between two criteria, while in the AHP, it is called the pairwise comparison. In this case, a total number of criteria, $n$, is the important criteria group selected from the screening step. Then, the DMs, for the second time, will give the influence score from 0 (no influence) to 4 (very high influence) between any two significant criteria.

$$
A=\left[\begin{array}{cccccc}
0 & a_{12} & \ldots & a_{1 j} & \ldots & a_{1 n} \\
a_{21} & 0 & \ldots & a_{2 j} & \ldots & a_{2 n} \\
\ldots & \ldots & \ldots & \ldots & \ldots & \ldots \\
\ldots & \ldots & \ldots & \ldots & \ldots & \ldots \\
a_{n 1} & a_{n 2} & \ldots & a_{n j} & \ldots & 0
\end{array}\right]
$$

\subsubsection{Calculating the normalized direct-relation} matrix (D)

The normalized direct-relation matrix $(D)$ including elements ranged from 0 to 1 is calculated using equation (8) .

$$
\begin{aligned}
& D=A \times S \\
& \text { where } \\
& S=\frac{1}{\max _{1 \leq i \leq n} \sum_{j=1}^{n} a_{i j}}
\end{aligned}
$$

\subsubsection{Calculating the total-relation matrix (T)} and the sum of rows and columns of the matrix

The total-relation matrix $(T)$ is obtained using equation (10) where $I$ denotes the identity matrix.

$$
T=D(I-D)^{-1} \quad(10)
$$

Then, the sum of rows $\left(R_{i}\right)$ and the sum of columns $\left(C_{j}\right)$ are calculated using equation (11) and (12), respectively. The $R_{i}$ and $C_{j}$ values are the essential element to develop a causal diagram and to indicate whether the criteria belongs to either cause or effect group.

$$
\begin{aligned}
& R_{i}=\left[\sum_{j=1}^{n} t_{i j}\right]_{n \times 1}=\left[t_{i}\right]_{n \times 1} \\
& C_{j}=\left[\sum_{i=1}^{n} t_{i j}\right]_{1 \times n}=\left[t_{j}\right]_{1 \times n} \\
& \text { where } \\
& i=1,2, \ldots, n \text { and } j=1,2, \ldots, n
\end{aligned}
$$

\subsubsection{Setting up a threshold value $(\alpha)$}

As described in the screening step, the threshold value in the DEMATEL method will also determine the influence relations between two criteria. A threshold value, $(\alpha)$, is represented by the average of the elements in matrix $T$, while the selected influential relations are indicated by the element value that is greater than $\alpha$ value.

\subsubsection{Visualizing causal relations}

The causal relations among criteria are visualized through the digraph. The digraph is developed by mapping the horizontal or prominence, $(R i+C j)$, and the vertical or relation, $(R i-C j)$, values of all the significant criteria. In addition, the relation values will also classify the criteria into two groups, which are "cause" group with positive relation values and "effect" group indicated by negative relation values. 


\section{RESULT AND DISCUSSION}

\subsection{The passengers' decision-making criteria}

This study involves three DMs' representatives, which are: service manager, senior staff, and a representative of frequent passengers community, to identifiy the passengers' decision-making criteria and to determine the pairwise scale of the criteria. Initially, the criteria are developed based on indepth interview and literature reviews especially in BRT' MCDM topics, while the classification of the criteria is adapted from a study conducted by Krisnawan (2017). Hence, there are 21 criteria categorized into four dimensions as in Table 2.

\subsection{The Fuzzy AHP decision-matrix for four dimensions}

Secondly, all 21 criteria weights in four dimensions, time $\left(C_{1}\right)$, service level $\left(C_{2}\right)$, accessibility $\left(C_{3}\right)$, and reliability $\left(C_{4}\right)$, are obtained using the geometrical mean technique as in equation (2). Fuzzy aggregated decisionmatrices as described in the following tables are the result of linguistic scale conversion previously defined by the three DMs. After the matrices are developed, the fuzzy weight for all criteria can be calculated as shown in Table 3 to Table 6 for time $\left(C_{1}\right)$, service level $\left(C_{2}\right)$, accessibility $\left(C_{3}\right)$, and reliability $\left(C_{4}\right)$, respectively.

\subsection{Global rank and criteria screening}

Global weights for 21 criteria are calculated using equation (5) reported by Table 7 . After the weights are obtained, the screening step is achieved by comparing the weight and $\alpha$-cut values for each dimension. The $\alpha$-cut values are calculated using equation (6) where $\alpha$-cut for $C_{1}$, $C_{2}, C_{3}$, and $C_{4}$ are respectively $0.200,0.167$, 0.167 dan 0.250 . The significant criteria are indicated when the weight of corresponding criteria is greater than the threshold so that the critical factors for time dimension are $C_{11}$ dan $C_{15}$, service level are $C_{22}, C_{24}$, and $C_{25}$, accessibility are $C_{31}, C_{34}, C_{35}$, and $C_{36}$, and reliability are $C_{43}$. The total number of the significant criteria achieved by screening step is 11 criteria which indicate that passengers conern on these criteria when deciding to use the BRT system.

\subsection{Matrices for the DEMATEL}

Table 8 shows the initial direct-relation matrix of 11 significant criteria. The elements in matrix $A$ indicate the level of influence between

Table 2. Criteria and the description of passengers' decision for Transjogja

\begin{tabular}{lll}
\hline Dimension & Criteria & Code \\
\hline Time $\left(C_{1}\right)$ & Travel time & $C_{11}$ \\
& Time to the nearest bus stop & $C_{12}$ \\
& Waiting time for the bus & $C_{13}$ \\
& Time duration of arrival & $C_{14}$ \\
& Total time for a trip (transit and travel) & $C_{15}$ \\
& Convenience at the station & $C_{21}$ \\
& Security at the station & $C_{22}$ \\
& Availability of information at the station & $C_{23}$ \\
& Convenience on the bus & $C_{24}$ \\
& Safety on the bus & $C_{25}$ \\
& Availability of information on the bus & $C_{26}$ \\
& The number of bus stations & $C_{31}$ \\
& The distance to the station from the origin & $C_{32}$ \\
& Route coverage & $C_{33}$ \\
& The distance from the station to the destination & $C_{34}$ \\
& The stations' coverage to strategic points & $C_{35}$ \\
& Cross-route accessibility & $C_{36}$ \\
& On time departure & $C_{41}$ \\
& Reliable payment system & $C_{42}$ \\
& On time arrival & $C_{43}$ \\
& Certainty of service & $C_{44}$ \\
\hline
\end{tabular}


Table 3. The fuzzy aggregated decision-matrix of Criteria $\left(C_{1}\right)$

\begin{tabular}{lllllll}
\hline & $\boldsymbol{C}_{\mathbf{1 1}}$ & $\boldsymbol{C}_{\mathbf{1 2}}$ & $\boldsymbol{C}_{\mathbf{1 3}}$ & $\boldsymbol{C}_{\mathbf{1 4}}$ & $\boldsymbol{C}_{\mathbf{1 5}}$ & Fuzzy Weight \\
\hline $\boldsymbol{C}_{\mathbf{1 1}}$ & $(1,1,1)$ & $(3.80,4.34,4.89)$ & $\ldots$ & $\ldots$ & $(1.66,1.94,2.22)$ & $(0.19,0.23,0.28)$ \\
$\boldsymbol{C}_{\mathbf{1 2}}$ & $(0.94,1.12,1.33)$ & $(1,1,1)$ & $\ldots$ & $\ldots$ & $(1.11,1.26,1.41)$ & $(0.11,0.13,0.17)$ \\
$\boldsymbol{C}_{\mathbf{1 3}}$ & $\ldots$ & $\ldots$ & $\ldots$ & $\ldots$ & $\ldots$ & $(0.15,0.18,0.22)$ \\
$\boldsymbol{C}_{\mathbf{1 4}}$ & $\ldots$ & $\ldots$ & $\ldots$ & $\ldots$ & $\ldots$ & $(0.17,0.21,0.25)$ \\
$\boldsymbol{C}_{\mathbf{1 5}}$ & $(2.02,2.30,2.60)$ & $(3.60,4.00,4.42)$ & $\ldots$ & $\ldots$ & $(1,1,1)$ & $(0.21,0.24,0.29)$ \\
\hline
\end{tabular}

Table 4. The fuzzy aggregated decision-matrix of Criteria $\left(C_{2}\right)$

\begin{tabular}{llllllll}
\hline & $\boldsymbol{C}_{\mathbf{2 1}}$ & $\boldsymbol{C}_{\mathbf{2 2}}$ & $\boldsymbol{C}_{\mathbf{2 3}}$ & $\boldsymbol{C}_{\mathbf{2 4}}$ & $\boldsymbol{C}_{25}$ & $\boldsymbol{C}_{26}$ & Fuzzy Weight \\
\hline $\boldsymbol{C}_{21}$ & $(1,1,1)$ & $(1.41,1.58,1.78)$ & $\ldots$ & $\ldots$ & $\ldots$ & $(1.83,2.21,2.60)$ & $(0.13,0.16,0.19)$ \\
$\boldsymbol{C}_{22}$ & $(2.06,2.26,2.47)$ & $(1,1,1)$ & $\ldots$ & $\ldots$ & $\ldots$ & $(3.01,3.45,3.90)$ & $(0.16,0.19,0.23)$ \\
$\boldsymbol{C}_{23}$ & $\ldots$ & $\ldots$ & $\ldots$ & $\ldots$ & $\ldots$ & $\ldots$ & $(0.08,0.10,0.12)$ \\
$\boldsymbol{C}_{\mathbf{2 4}}$ & $\ldots$ & $\ldots$ & $\ldots$ & $\ldots$ & $\ldots$ & $\ldots$ & $(0.14,0.17,0.21)$ \\
$\boldsymbol{C}_{25}$ & $\ldots$ & $\ldots$ & $\ldots$ & $\ldots$ & $\ldots$ & $\ldots$ & $(0.19,0.23,0.27)$ \\
$\boldsymbol{C}_{\mathbf{2 6}}$ & $(2.18,2.57,2.98)$ & $(1.67,1.92,2.17)$ & $\ldots$ & $\ldots$ & $\ldots$ & $(1,1,1)$ & $(0.13,0.15,0.19)$ \\
\hline
\end{tabular}

Table 5. The fuzzy aggregated decision-matrix of Criteria $\left(C_{3}\right)$

\begin{tabular}{llllllll}
\hline & $\boldsymbol{C}_{\mathbf{3 1}}$ & $\boldsymbol{C}_{\mathbf{3 2}}$ & $\boldsymbol{C}_{\mathbf{3 3}}$ & $\boldsymbol{C}_{\mathbf{3 4}}$ & $\boldsymbol{C}_{\mathbf{3 5}}$ & $\boldsymbol{C}_{\mathbf{3 6}}$ & Fuzzy Weight \\
\hline $\boldsymbol{C}_{\mathbf{3 1}}$ & $(1,1,1)$ & $(2.99,3.50,4.02)$ & $\ldots$ & $\ldots$ & $\ldots$ & $(1.61,1.82,2.03)$ & $(0.16,0.20,0.26)$ \\
$\boldsymbol{C}_{\mathbf{3 2}}$ & $(0.80,0.95,1.12)$ & $(1,1,1)$ & $\ldots$ & $\ldots$ & $\ldots$ & $(1.49,1.70,1.91)$ & $(0.12,0.15,0.19)$ \\
$\boldsymbol{C}_{\mathbf{3 3}}$ & $\ldots$ & $\ldots$ & $\ldots$ & $\ldots$ & $\ldots$ & $\ldots$ & $(0.11,0.14,0.17)$ \\
$\boldsymbol{C}_{\mathbf{3 4}}$ & $\ldots$ & $\ldots$ & $\ldots$ & $\ldots$ & $\ldots$ & $\ldots$ & $(0.14,0.17,0.22)$ \\
$\boldsymbol{C}_{\mathbf{3 5}}$ & $\ldots$ & $\ldots$ & $\ldots$ & $\ldots$ & $\ldots$ & $\ldots$ & $(0.13,0.17,0.21)$ \\
$\boldsymbol{C}_{\mathbf{3 6}}$ & $(1.96,2.23,2.51)$ & $(2.27,2.62,2.97)$ & $\ldots$ & $\ldots$ & $\ldots$ & $(1,1,1)$ & $(0.14,0.17,0.21)$ \\
\hline
\end{tabular}

Table 6. The fuzzy aggregated decision-matrix of Criteria $\left(C_{4}\right)$

\begin{tabular}{llllll}
\hline & $\boldsymbol{C}_{\mathbf{4 1}}$ & $\boldsymbol{C}_{\mathbf{4 2}}$ & $\boldsymbol{C}_{\mathbf{4 3}}$ & $\boldsymbol{C}_{\mathbf{4 4}}$ & Fuzzy Weight \\
\hline $\boldsymbol{C}_{\mathbf{4 1}}$ & $(1,1,1)$ & $(2.05,2.39,2.74)$ & $(1.21,1.39,1.56)$ & $(2.25,2.67,3.09)$ & $(0.20,0.24,0.29)$ \\
$\boldsymbol{C}_{\mathbf{4 2}}$ & $(2.56,2.71,2.87)$ & $(1,1,1)$ & $(0.95,1.20,1.46)$ & $(1.09,1.24,1.40)$ & $(0.16,0.20,0.24)$ \\
$\boldsymbol{C}_{\mathbf{4 3}}$ & $(2.46,2.74,3.01)$ & $(2.89,3.30,3.74)$ & $(1,1,1)$ & $(3.46,3.86,4.26)$ & $(0.28,0.34,0.40)$ \\
$\boldsymbol{C}_{\mathbf{4 4}}$ & $(1.99,2.27,2.55)$ & $(1.93,2.17,2.41)$ & $(1.42,1.54,1.67)$ & $(1,1,1)$ & $(0.19,0.23,0.27)$ \\
\hline
\end{tabular}

Table 7. Criteria weights and screening result based on the $\alpha$-cut

\begin{tabular}{|c|c|c|c|c|c|}
\hline Dimension & Criteria & Weight & Dimension & Criteria & Weight \\
\hline Time $\left(C_{1}\right)$ & $C_{11}$ & $0.230 *$ & Accessibility $\left(C_{3}\right)$ & $C_{31}$ & $0.203^{*}$ \\
\hline \multirow[t]{5}{*}{$\alpha-$ cut $=0.200$} & $C_{12}$ & 0.134 & $\alpha$-cut $=0.167$ & $C_{32}$ & 0.149 \\
\hline & $C_{13}$ & 0.183 & & $C_{33}$ & 0.138 \\
\hline & $C_{14}$ & $0.209 *$ & & $C_{34}$ & $0.173 *$ \\
\hline & $C_{15}$ & $0.244^{*}$ & & $C_{35}$ & $0.167 *$ \\
\hline & & & & $C_{36}$ & $0.169^{*}$ \\
\hline Service level $\left(C_{2}\right)$ & $C_{21}$ & 0.156 & Reliability $\left(C_{4}\right)$ & $C_{41}$ & 0.239 \\
\hline \multirow[t]{5}{*}{$\alpha$-cut $=0.167$} & $C_{22}$ & $0.190 *$ & $\alpha$-cut $=0.250$ & $C_{42}$ & 0.196 \\
\hline & $C_{23}$ & 0.098 & & $C_{43}$ & $0.336^{*}$ \\
\hline & $C_{24}$ & $0.174 *$ & & $C_{44}$ & 0.229 \\
\hline & $C_{25}$ & $0.228^{*}$ & & & \\
\hline & $C_{26}$ & 0.154 & & & \\
\hline
\end{tabular}

${ }^{*}$ weight value is greater than the $\alpha$-cut

the two criteria. For instance, the $C_{11}$ criterion has a very high influence on $C_{43}$. Further, the matrix $A$ includes significant criteria of four distinct dimensions so that a higher influence will be indicated by the criteria that have the different dimension. For instance, the criterion 
of travel time, $C_{11}$, has a low influence on the criteria of $C_{14}$ and $C_{15}$ since these comparisons are from the same dimension, $C_{1}$. Meanwhile, higher influences will be experienced when $C_{11}$ is compared to the criteria in different dimensions such as $C_{24}, C_{34}, C_{35}, C_{36}$, and $C_{43}$ which indicate very high influences, although it is still possible to obtain low influences even no influence depends on the DMs' assessment. Subsequently, the normalized direct-relation matrix $(D)$ is developed using equation $(8)$ as reported in Table 9, while Table 10 shows the total-relation matrix $(T)$ calculated using equation (10). The elements in matrix $T$ are obtained by multiplying elements in matrix $D$, Table 9, with the identity matrix $(I)$ for the $11 \times 11$ matrix.

\subsection{The causal relations described by influential matrix and digraph}

Table 11 provided components of digraph, namely the horizontal axis, $(R i+C j)$, and the vertical axis, $(R i-C j)$. The value of $R_{i}$ and $C_{j}$ is the sum of the rows and the columns of the matrix $T$ as described in equation (11) and (12). Furthermore, the significant criteria are categorized into two groups, namely cause group and effect group. The determination of the

Table 8. The initial direct-relation matrix $(A)$ for the significant criteria

\begin{tabular}{lccccccccccc}
\hline & $\boldsymbol{C}_{\mathbf{1 1}}$ & $\boldsymbol{C}_{\mathbf{1 4}}$ & $\boldsymbol{C}_{\mathbf{1 5}}$ & $\boldsymbol{C}_{\mathbf{2 2}}$ & $\boldsymbol{C}_{\mathbf{2 4}}$ & $\boldsymbol{C}_{\mathbf{2 5}}$ & $\boldsymbol{C}_{\mathbf{3 1}}$ & $\boldsymbol{C}_{\mathbf{3 4}}$ & $\boldsymbol{C}_{\mathbf{3 5}}$ & $\boldsymbol{C}_{\mathbf{3 6}}$ & $\boldsymbol{C}_{\mathbf{4 3}}$ \\
\hline $\boldsymbol{C}_{\mathbf{1 1}}$ & 0 & 1 & 1 & 3 & 4 & 0 & 2 & 4 & 4 & 4 & 4 \\
$\boldsymbol{C}_{\mathbf{1 4}}$ & 1 & 0 & 1 & 2 & 3 & 1 & 1 & 3 & 4 & 4 & 4 \\
$\boldsymbol{C}_{\mathbf{1 5}}$ & 1 & 2 & 0 & 3 & 4 & 1 & 2 & 4 & 4 & 4 & 4 \\
$\boldsymbol{C}_{\mathbf{2 2}}$ & 1 & 1 & 2 & 0 & 3 & 1 & 0 & 3 & 4 & 4 & 4 \\
$\boldsymbol{C}_{\mathbf{2 4}}$ & 1 & 1 & 2 & 0 & 0 & 1 & 1 & 1 & 4 & 3 & 4 \\
$\boldsymbol{C}_{\mathbf{2 5}}$ & 0 & 1 & 1 & 3 & 4 & 0 & 2 & 4 & 4 & 4 & 4 \\
$\boldsymbol{C}_{\mathbf{3 1}}$ & 1 & 0 & 1 & 1 & 3 & 1 & 0 & 3 & 4 & 4 & 4 \\
$\boldsymbol{C}_{\mathbf{3 4}}$ & 1 & 1 & 2 & 0 & 0 & 1 & 1 & 0 & 4 & 3 & 4 \\
$\boldsymbol{C}_{\mathbf{3 5}}$ & 2 & 1 & 2 & 1 & 0 & 1 & 1 & 0 & 0 & 0 & 4 \\
$\boldsymbol{C}_{\mathbf{3 6}}$ & 2 & 1 & 2 & 1 & 0 & 1 & 1 & 0 & 4 & 0 & 4 \\
$\boldsymbol{C}_{\mathbf{4 3}}$ & 3 & 3 & 2 & 4 & 4 & 3 & 3 & 4 & 4 & 4 & 0 \\
\hline
\end{tabular}

Table 9. The normalized direct-relation matrix $(D)$ for the significant criteria

\begin{tabular}{lrrrrrrrrrrr}
\hline & $\boldsymbol{C}_{\mathbf{1 1}}$ & $\boldsymbol{C}_{\mathbf{1 4}}$ & $\boldsymbol{C}_{\mathbf{1 5}}$ & $\boldsymbol{C}_{\mathbf{2 2}}$ & $\boldsymbol{C}_{\mathbf{2 4}}$ & $\boldsymbol{C}_{\mathbf{2 5}}$ & $\boldsymbol{C}_{\mathbf{3 1}}$ & $\boldsymbol{C}_{\mathbf{3 4}}$ & $\boldsymbol{C}_{\mathbf{3 5}}$ & $\boldsymbol{C}_{\mathbf{3 6}}$ & $\boldsymbol{C}_{\mathbf{4 3}}$ \\
\hline $\boldsymbol{C}_{\mathbf{1 1}}$ & 0.000 & 0.029 & 0.029 & 0.088 & 0.118 & 0.000 & 0.059 & 0.118 & 0.118 & 0.118 & 0.118 \\
$\boldsymbol{C}_{\mathbf{1 4}}$ & 0.029 & 0.000 & 0.029 & 0.059 & 0.088 & 0.029 & 0.029 & 0.088 & 0.118 & 0.118 & 0.118 \\
$\boldsymbol{C}_{\mathbf{1 5}}$ & 0.029 & 0.059 & 0.000 & 0.088 & 0.118 & 0.029 & 0.059 & 0.118 & 0.118 & 0.118 & 0.118 \\
$\boldsymbol{C}_{\mathbf{2 2}}$ & 0.029 & 0.029 & 0.059 & 0.000 & 0.088 & 0.029 & 0.000 & 0.088 & 0.118 & 0.118 & 0.118 \\
$\boldsymbol{C}_{\mathbf{2 4}}$ & 0.029 & 0.029 & 0.059 & 0.000 & 0.000 & 0.029 & 0.029 & 0.029 & 0.118 & 0.088 & 0.118 \\
$\boldsymbol{C}_{\mathbf{2 5}}$ & 0.000 & 0.029 & 0.029 & 0.088 & 0.118 & 0.000 & 0.059 & 0.118 & 0.118 & 0.118 & 0.118 \\
$\boldsymbol{C}_{\mathbf{3 1}}$ & 0.029 & 0.000 & 0.029 & 0.029 & 0.088 & 0.029 & 0.000 & 0.088 & 0.118 & 0.118 & 0.118 \\
$\boldsymbol{C}_{\mathbf{3 4}}$ & 0.029 & 0.029 & 0.059 & 0.000 & 0.000 & 0.029 & 0.029 & 0.000 & 0.118 & 0.088 & 0.118 \\
$\boldsymbol{C}_{\mathbf{3 5}}$ & 0.059 & 0.029 & 0.059 & 0.029 & 0.000 & 0.029 & 0.029 & 0.000 & 0.000 & 0.000 & 0.118 \\
$\boldsymbol{C}_{\mathbf{3 6}}$ & 0.059 & 0.029 & 0.059 & 0.029 & 0.000 & 0.029 & 0.029 & 0.000 & 0.118 & 0.000 & 0.118 \\
$\boldsymbol{C}_{\mathbf{4 3}}$ & 0.088 & 0.088 & 0.059 & 0.118 & 0.118 & 0.088 & 0.088 & 0.118 & 0.118 & 0.118 & 0.000 \\
\hline
\end{tabular}

Table 10. The total-relation matrix $(T)$ for the significant criteria

\begin{tabular}{llllllrrrrrr}
\hline & $\boldsymbol{C}_{\mathbf{1 1}}$ & $\boldsymbol{C}_{\mathbf{1 4}}$ & $\boldsymbol{C}_{\mathbf{1 5}}$ & $\boldsymbol{C}_{\mathbf{2 2}}$ & $\boldsymbol{C}_{\mathbf{2 4}}$ & $\boldsymbol{C}_{\mathbf{2 5}}$ & $\boldsymbol{C}_{\mathbf{3 1}}$ & $\boldsymbol{C}_{\mathbf{3 4}}$ & $\boldsymbol{C}_{\mathbf{3 5}}$ & $\boldsymbol{C}_{\mathbf{3 6}}$ & $\boldsymbol{C}_{\mathbf{4 3}}$ \\
\hline $\boldsymbol{C}_{\mathbf{1 1}}$ & 0.097 & 0.110 & 0.137 & 0.184 & 0.232 & 0.078 & 0.142 & 0.239 & 0.334 & 0.286 & 0.334 \\
$\boldsymbol{C}_{\mathbf{1 4}}$ & 0.116 & 0.074 & 0.125 & 0.150 & 0.194 & 0.099 & 0.108 & 0.200 & 0.311 & 0.268 & 0.311 \\
$\boldsymbol{C}_{\mathbf{1 5}}$ & 0.131 & 0.143 & 0.116 & 0.193 & 0.244 & 0.112 & 0.149 & 0.251 & 0.352 & 0.302 & 0.352 \\
$\boldsymbol{C}_{\mathbf{2 2}}$ & 0.113 & 0.102 & 0.150 & 0.093 & 0.191 & 0.097 & 0.079 & 0.196 & 0.304 & 0.262 & 0.304 \\
$\boldsymbol{C}_{\mathbf{2 4}}$ & 0.099 & 0.089 & 0.131 & 0.081 & 0.092 & 0.085 & 0.094 & 0.124 & 0.267 & 0.207 & 0.267 \\
$\boldsymbol{C}_{\mathbf{2 5}}$ & 0.097 & 0.110 & 0.137 & 0.184 & 0.232 & 0.078 & 0.142 & 0.239 & 0.334 & 0.286 & 0.334 \\
$\boldsymbol{C}_{\mathbf{3 1}}$ & 0.109 & 0.069 & 0.118 & 0.115 & 0.183 & 0.093 & 0.074 & 0.189 & 0.294 & 0.253 & 0.294 \\
$\boldsymbol{C}_{\mathbf{3 4}}$ & 0.096 & 0.086 & 0.127 & 0.079 & 0.089 & 0.082 & 0.092 & 0.092 & 0.259 & 0.201 & 0.259 \\
$\boldsymbol{C}_{\mathbf{3 5}}$ & 0.108 & 0.076 & 0.111 & 0.096 & 0.083 & 0.072 & 0.081 & 0.086 & 0.123 & 0.106 & 0.228 \\
$\boldsymbol{C}_{\mathbf{3 6}}$ & 0.121 & 0.085 & 0.124 & 0.107 & 0.093 & 0.080 & 0.090 & 0.096 & 0.255 & 0.118 & 0.255 \\
$\boldsymbol{C}_{\mathbf{4 3}}$ & 0.196 & 0.180 & 0.187 & 0.238 & 0.271 & 0.175 & 0.189 & 0.279 & 0.393 & 0.337 & 0.288 \\
\hline
\end{tabular}


Table 11. The group for the significant criteria

\begin{tabular}{lllll}
\hline $\boldsymbol{C o d e}$ & Criteria & $\boldsymbol{R} \boldsymbol{i}+\boldsymbol{C} \boldsymbol{j}$ & $\boldsymbol{R i}-\boldsymbol{C} \boldsymbol{j}$ & Group \\
\hline $\boldsymbol{C}_{\mathbf{1 1}}$ & Travel time & 3.455 & 0.889 & Cause \\
$\boldsymbol{C}_{\mathbf{1 4}}$ & Time duration of arrival & 3.081 & 0.834 & Cause \\
$\boldsymbol{C}_{\mathbf{1 5}}$ & Total time for a trip (transit and travel) & 3.808 & 0.886 & Cause \\
$\boldsymbol{C}_{\mathbf{2 2}}$ & Security at the station & 3.409 & 0.372 & Cause \\
$\boldsymbol{C}_{\mathbf{2 4}}$ & Convenience on the bus & 3.437 & -0.371 & Effect \\
$\boldsymbol{C}_{\mathbf{2 5}}$ & Safety on the bus & 3.224 & 1.120 & Cause \\
$\boldsymbol{C}_{\mathbf{3 1}}$ & The number of bus stations & 3.030 & 0.551 & Cause \\
$\boldsymbol{C}_{\mathbf{3 4}}$ & The distance from the station to the destination & 3.450 & -0.529 & Effect \\
$\boldsymbol{C}_{\mathbf{3 5}}$ & The stations' coverage to strategic points & 4.396 & -2.056 & Effect \\
$\boldsymbol{C}_{\mathbf{3 6}}$ & Cross-route accessibility & 4.052 & -1.201 & Effect \\
$\boldsymbol{C}_{\mathbf{4 3}}$ & On time arrival & 5.958 & -0.494 & Effect \\
\hline
\end{tabular}

Table 12. Influential relationship for 11 criteria

\begin{tabular}{|c|c|c|}
\hline \multicolumn{3}{|r|}{ Causal relations } \\
\hline$C_{11}$ & $\rightarrow$ & $C_{22}, C_{24}, C_{34}, C_{35}{ }^{*}, C_{36}, C_{43}{ }^{*}$ \\
\hline$C_{14}$ & $\rightarrow$ & $C_{24}, C_{34}, C_{35}{ }^{*}, C_{36}, C_{43}{ }^{*}$ \\
\hline$C_{15}$ & $\rightarrow$ & $C_{22}, C_{24}, C_{34}, C_{35}{ }^{*}, C_{36}, C_{43}{ }^{*}$ \\
\hline$C_{22}$ & $\rightarrow$ & $C_{24}, C_{34}, C_{35}{ }^{*}, C_{36}, C_{43}{ }^{*}$ \\
\hline$C_{24}$ & $\rightarrow$ & $C_{35}{ }^{*}, C_{36}, C_{43}{ }^{*}$ \\
\hline$C_{25}$ & $\rightarrow$ & $C_{22}, C_{24}, C_{34}, C_{35}{ }^{*}, C_{36}, C_{43}{ }^{*}$ \\
\hline$C_{31}$ & $\rightarrow$ & $C_{24}, C_{34}, C_{35}{ }^{*}, C_{36}, C_{43}{ }^{*}$ \\
\hline$C_{34}$ & $\rightarrow$ & $C_{35}{ }^{*}, C_{36}, C_{43}{ }^{*}$ \\
\hline$C_{35}$ & $\rightarrow$ & $C_{43}{ }^{*}$ \\
\hline$C_{36}$ & $\rightarrow$ & $C_{35^{*}}, C_{43}{ }^{*}$ \\
\hline$C_{43}$ & & $C_{11}, C_{14}, C_{15}, C_{22}, C_{24}, C_{25}, C_{31}, C_{34}, C_{35}{ }^{*}, C_{36}, C_{43}$ \\
\hline
\end{tabular}

criteria group is based on the value of the vertical axis which represents the "relation" value provided that the positive relation value is included to the cause group while the negative relation value belongs to the effect group.

As can be seen in Table 11, there are six criteria that are classified into cause group, which are: $C_{11}, C_{14}, C_{15}, C_{22}, C_{25}$, and $C_{31}$, and five criteria included in effect group, namely $C_{24}, C_{34}, C_{35}, C_{36}$, and $C_{43}$. All time dimension $\left(C_{1}\right)$ criteria are causal criteria as the time is deemed an essential reason when passengers using Transjogja service; meanwhile, although most of the criteria on the accessibility $\left(C_{3}\right)$ are the effect group, the number of bus stations $\left(C_{31}\right)$ is also a contributing factor when the bus service may be improved including the ability to reach destination more efficiently as well as service reliability. Then, the criteria relationship mapping can be determined based on threshold value, $\alpha$, and the elements in matrix $T$. The threshold value obtained is 0.171 and the elements in the matrix $T$ will represent an influential relationship when the value is greater than the threshold. For instance, the $C_{11}$ has influences on six other criteria, which are: $C_{22}$,
$C_{24}, C_{34}, C_{35}, C_{36}$, and $C_{43}$, since the values of $C_{11}$ to $C_{22}, C_{11}$ to $C_{24}, C_{11}$ to $C_{34}, C_{11}$ to $C_{35}, C_{11}$ to $C_{36}$, and $C_{11}$ to $C_{43}$ are respectively $0.184,0.232$, $0.239,0.334,0.286,0.334$. The influential relations mapping for the 11 criteria is shown in Table 12.

As seen in Table 12, the criteria of $C_{35}$ and $C_{43}$ are both criteria with an asterisk indicating that these two criteria are the key factors which have the maximum effect value over the other criteria. Moreover, both criteria are the key effect criteria as the criteria will be highly considered from the other criteria levels. In a decision-making practice, the DMs are advised to consider these two criteria, namely coverage to strategic locations and on time arrival, when improving the quality of the Transjogja service, especially on time arrival which may not only effect receiver but also bring significant effect to all criteria as illustrated in Figure 1.

Coverage to strategic locations and on time arrival criteria are critical reasons for passengers choosing Transjogja since initially passengers may review whether their destinations are within coverage, even due to the tourist region, tourists will consider some tourist attractions' access. 
Thus, to increase the number of coverages, the DMs are required to evaluate the other significant factors such as the factor for time, comfort and safety, the number of fleets, and cross-lane integration. In addition, the on time arrival criterion experiences the most extreme prominence value of 5.958; moreover, this criterion has also the highest weight of 0.336 as reported in Fuzzy AHP. This indicates that on time arrival is a fundamental parameter which represents all dimensions of passengers' decision. Although $C_{43}$ belongs to the effect group, the degree of relation is not as extreme as $C_{35}$ which hit a low of -2.056 so that in the digraph the $C_{43}$ has significant influences on all criteria. Hence, the DMs can improve the Transjogja's performance to be the most preferred public transportation in the region by evaluating 11 significant criteria out of the 21 identified criteria, especially the two criteria, namely coverage to strategic destinations and on time arrival, put as top priority.

This study is in line with the study carried out by Octaviantari (2016) in which the two key factors identified, coverage to strategic destinations $\left(C_{35}\right)$ and on time arrival $\left(C_{43}\right)$, were considered to become highly suggested factors for the BRT' service improvement. Octaviantari (2016) reported that the coverage to strategic destinations criterion was the lowest perceived factor in the current BRT' service, while the on time arrival criterion was identified as the highest expected factor demanded by passengers. However, the study by Octaviantari (2016) has not been able to rank the most important factor, although mapping which factors belong to the low perceive and the high expectation into the quadrants. Further, it is assumed that the DMs are required to implement multi improvements involving a number of criteria suggested. By contrast, with this integrated Fuzzy AHP - DEMATEL method, this study successfully ranks the passengers' decision factors when using Transjogja service which can be extended for common decisionmaking problems in transportation systems

Besides, by using the same framework as Octaviantari (2016), Transistari (2017) analyzed passengers' satisfaction factors on Transjogja services using the importance performance analysis. Interestingly, on time arrival criterion has also been classified by Transistari (2017) as one of the critical factors that must be solved. Then, the study conducted by Transistari (2017) might emphasize BRT' staff performances when serving passengers that have also been discussed in the two other studies by Sutari \& Herlina (2020) and Wibowo (2014). Despite a similarity in defining two critical factors especially in the finding delivered by Octaviantari (2016), the

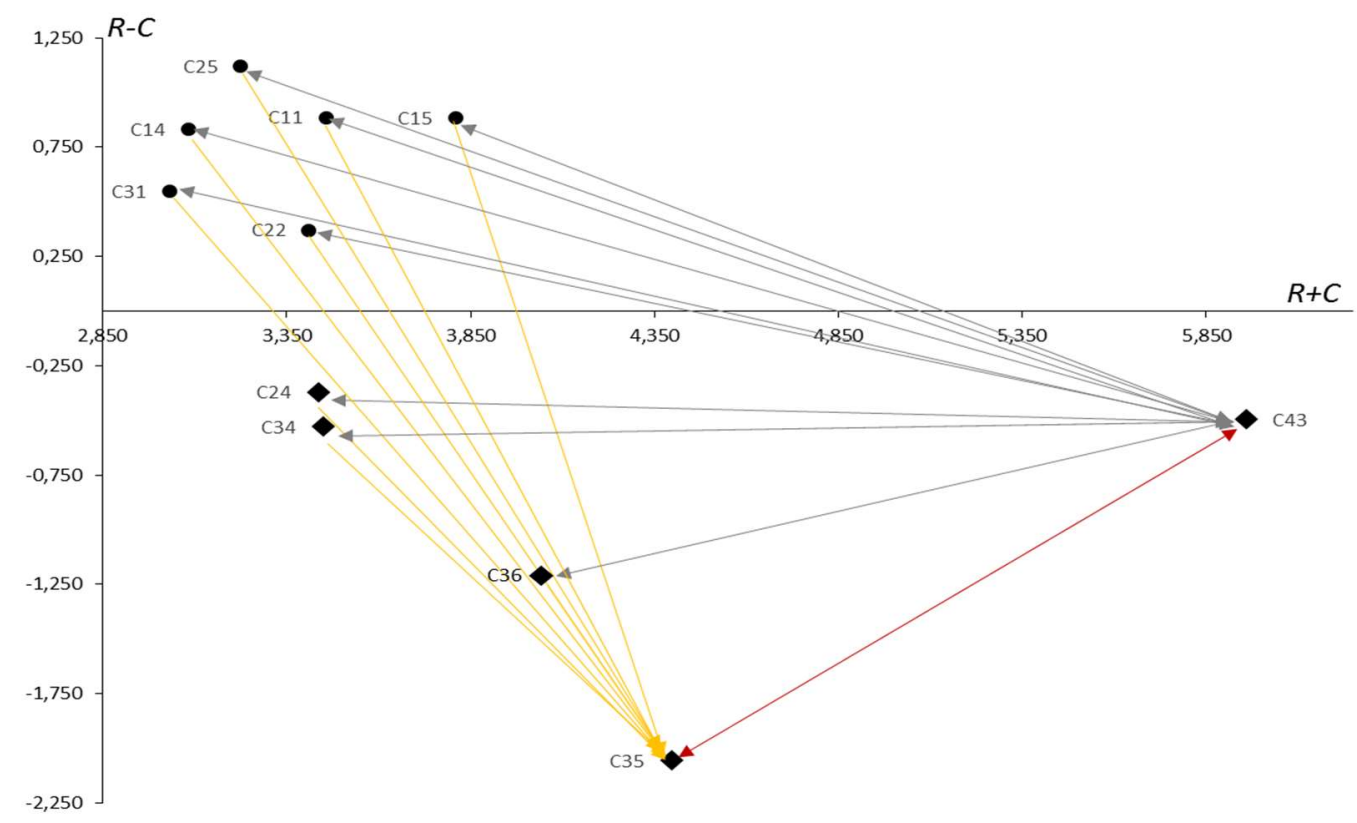

Figure 1. The digraph for the two-priority criteria, $C_{35}$ dan $C_{43}$ 
other studies examining public transportation services demonstrated in Transjogja system would prefer to map or classify the passengers' service factors only into the determined groups. Meanwhile, the MCDM techniques used in this study are proven to be able to not only map the criteria but also prioritize the significant criteria as well as investigate the relations to obtain the most influencing criteria. Accordingly, by giving attention to the key criteria at the most, the DMs will be able to improve the system from the practical level, and of course, it is more applicable.

\section{CONCLUSION}

In conclusion, this study provides a comprehensive result for evaluating the performance of the BRT system demonstrated in a case study of Transjogja with the decisionmaking approaches. First, this study succeeded in selecting significant criteria from many identified criteria, and second, this study also elaborates the relationship among these key criteria so that it is able to provide an advice to decision-makers if improvements to Transjogja service are needed. The result indicates that there are 11 out of 21 criteria that have a significant value, while from these significant criteria, the DMs can prioritize coverage to strategic points and on time arrival to improve the BRT performance. The improvement in these key indicators supports the government to encourage passengers, especially in the region of Yogyakarta, to take Transjogja with many benefits.

Although this research can investigate decision-making factors in terms of service aspect, other parameters such as economic and environmental aspect should be added to future research. Additional discussion from other factors is believed to strengthen the DMs' policies to improve public transportation services and to increase the number of passengers; further, a decision-making standard that can be implemented in other regions may be achieved.

\section{REFERENCES}

Aminah, S. (2018). Transportasi Publik dan Aksesibilitas Masyarakat Perkotaan. Jurnal Teknik Sipil UBL, 9(1), 11421155.
Azali, I., Gunanto, E. Y. A., \& SBM, N. (2018). Preferensi Konsumen Terhadap Transportasi Publik (Studi Kasus Bus Rapid Transit (BRT) Kota Semarang). Media Ekonomi Dan Manajemen, 33(1). https://doi.org/10.24856/mem.v33i1.617

Bakır, M., Akan, Ş., \& Durmaz, E. (2019). Exploring Service Quality of Low-Cost Airlines in Europe: an Integrated MCDM Approach. Economics and Business Review, 5(2), 109-130. https://doi.org/10.18559/ebr.2019.2.6

Chen, I. S. (2016). A combined MCDM model based on DEMATEL and ANP for the selection of airline service quality improvement criteria: A study based on the Taiwanese airline industry. Journal of Air Transport Management, 57, 7-18. https://doi.org/10.1016/j.jairtraman.2016. 07.004

Chou, Y. C., Yen, H. Y., Dang, V. T., \& Sun, C. C. (2019). Assessing the human resource in science and technology for Asian countries: Application of fuzzy AHP and fuzzy TOPSIS. Symmetry, 11(2). https://doi.org/10.3390/sym11020251

Duleba, S., \& Moslem, S. (2018). Sustainable urban transport development with stakeholder participation, an AHPKendall model: A case study for Mersin. Sustainability (Switzerland), 10(10). https://doi.org/10.3390/su10103647

Kab. Kampar, D. (2019). 8 Keuntungan Saat Naik Transportasi Umum, Apa Saja? Retrieved from https://dishub.kamparkab.go.id/2019/04/ 22/8-keuntungan-saat-naik-transportasiumum-apa-saja/

Kiani Mavi, R., Zarbakhshnia, N., \& Khazraei, A. (2018). Bus rapid transit (BRT): A simulation and multi criteria decision making (MCDM) approach. Transport Policy, 72(March), 187-197. https://doi.org/10.1016/j.tranpol.2018.03. 010

Krisnawan, A. D. (2017). Penerapan Metode Analytical Hierarchy Process (AHP) dan Quality Function Deployment (QFD) untuk Menentukan Preferensi Bus Transjogja. Universitas Sarjanawiyata Tamansiswa.

Li, X. H., Huang, L., Li, Q., \& Liu, H. C. (2020). Passenger satisfaction evaluation of 
public transportation using pythagorean fuzzy MULTIMOORA method under large group environment. Sustainability (Switzerland), https://doi.org/10.3390/su12124996

Lova, C. (2019). BPTJ: Penggunaan Transportasi Umum Baru 30 Persen di Jabodetabek. Retrieved from https://megapolitan.kompas.com/read/20 19/11/14/14224231/bptj-penggunaantransportasi-umum-baru-30-persen-dijabodetabek

Mardani, A., Zavadskas, E. K., Khalifah, Z., Jusoh, A., \& Nor, K. M. D. (2016). Multiple criteria decision-making techniques in transportation systems: a systematic review of the state of the art literature. Transport, 31(3), 359-385. https://doi.org/10.3846/16484142.2015.1 121517

Moslem, S., Alkharabsheh, A., Ismael, K., \& Duleba, S. (2020). An integrated decision support model for evaluating public transport quality. Applied Sciences (Switzerland), 10(12), 1-19. https://doi.org/10.3390/APP10124158

Nassereddine, M., \& Eskandari, H. (2017). An integrated MCDM approach to evaluate public transportation systems in Tehran. Transportation Research Part A: Policy and Practice, 106(October), 427-439. https://doi.org/10.1016/j.tra.2017.10.013

Octaviantari, R. N. (2016). Importance Performance Analysis Bus Trans Jogja. (October), 11-13.

Perhubungan, K. (2019). Informasi Transportasi 2018.

Shieh, J. I., Wu, H. H., \& Huang, K. K. (2010). A DEMATEL method in identifying key success factors of hospital service quality. Knowledge-Based Systems, 23(3), 277282. https://doi.org/10.1016/j.knosys.2010.01. 013
Sutari, I., \& Herlina, S. (2020). Analisis Pengaruh Kualitas Layanan terhadap Kepuasan Pelanggan Menggunakan Jasa Transportasi Trans Jogja di Kota Yogyakarta. Equilibrium Jurnal Bisnis \& Akuntansi, XIV(1), 68-82.

Transistari, R. (2017). Transistari: The Use of Importance Performance Analysis to Evaluate.... XXII(01), 95-108.

Wibowo, A. (2014). Pengaruh Kualitas Pelayanan Transportasi Umumbus Trans Jogja Terhadap Kepuasan Konsumen. Jurnal Ilmu Manajemen, 11(2), 67-81. https://doi.org/10.21831/jim.v11i2.11765

Yang, J. J., Chuang, Y. C., Lo, H. W., \& Lee, T. I. (2020). A two-stage MCDM model for exploring the influential relationships of sustainable sports tourism criteria in Taichung City. International Journal of Environmental Research and Public Health, 17(7). https://doi.org/10.3390/ijerph17072319

Yazdani, M., Torkayesh, A. E., \& Chatterjee, P. (2020). An integrated decision-making model for supplier evaluation in public healthcare system: the case study of a Spanish hospital. Journal of Enterprise Information Management. https://doi.org/10.1108/JEIM-09-20190294

Zapolskyte, S., Burinskienė, M., \& Trépanier, M. (2020). Evaluation criteria of smart city mobility system using MCDM method. Baltic Journal of Road and Bridge Engineering, 15(4), 196-224. https://doi.org/10.7250/bjrbe.202015.501 